\title{
GYNODIOECY IN PLANTAGO LANCEOLATA L. III. SEXUAL REPRODUCTION AND THE MAINTENANCE OF MALE STERILES*
}

\author{
J. M. M. VAN DAMME† \\ Department of Genetics, University of Groningen, Biology Centre, Kerklaan 30, 9751 NN \\ Haren (The Netherlands)
}

Received 8 vii. 83

\begin{abstract}
SUMMARY
The importance of the reproductive part of the life cycle for the maintenance of the gynodioecious breeding system in Plantago lanceolata has been studied. Two male sterility types (MS1, MS2), the corresponding partial male sterility types or intermediates (IN1, IN2) and hermaphrodites (H) have been compared in four populations for seed production (ovule production [ ] female fertility) and weight per seed. MS1 plants produce more and heavier seeds than hermaphrodites. MS2 produces more ovules than $\mathrm{H}$, but it is partially female sterile, so that seed production does not differ significantly between the two phenotypes. Because MS2 in addition has a lower weight per seed, it has no advantage in reproduction via seeds over any other sex type. The results for the intermediate sex types indicate that overdominance at sex determining loci may be involved in the maintenance of MS2. Reproductive differences between genotypes within the $\mathbf{H}$ phenotype have been found in a cultivation experiment, in accordance with theoretical models, which concerns variation in pollen production, associated with plasmon type. The mechanism of partial female sterility is discussed. The observed differences between sex types are interpreted as pleiotropic effects of the male sterility genes. It is argued that while the differences between male steriles and hermaphrodites in sexual reproduction contribute to the maintenance of gynodioecy, they probably do not explain it fully.
\end{abstract}

\section{INTRODUCTION}

In a gynodioecious species some plants are by definition unable to transfer their genes to the next generation via pollen, while all plants can do so via ovules. In this breeding system there are essentially two sex phenotypes, male steriles and hermaphrodites, which can only coexist under specific conditions. Numerous theoretical studies have shown that male steriles, which are at a disadvantage, can be maintained only if they produce more viable offspring than hermaphrodites do, the exact amount needed depending on the mode of inheritance of male sterility (Lloyd, 1974; Ross, 1978; Charlesworth, 1981; and others). Such a fitness difference can be achieved in various ways and through various parts of the life cycle. An obvious object for studying differences between sex types is the number and weight of seeds produced and these characters have been frequently studied. Total seed weight production can be divided into seed production (the product of flower production and number of seeds per flower) and weight per seed. In earlier studies, beginning with Darwin (1877), differences between male steriles and hermaphrodites in one or more of these components have been

* Grassland Species Research Group Publication no. 67.

† Present address: Institute of Ecological Research, Department of Dune Research "Weevers' Duin", Duinzoom 20a, 3233 EG Oostvoorne (The Netherlands). 
found. In some species differences in seed number per flower appeared to be very large and in favour of male steriles, from which subdioecy was concluded (Burrows, 1960; Arroyo and Raven, 1975; Webb, 1979). In other species, differences between the two forms were less extreme and the contribution of the various components of seed weight production to these differences varied from species to species (Assouad et al., 1978; Philipp, 1980; Vaarama and Jääskeläinen, 1967). However, not only the size of these differences but also their origin is important. In stable gynodioecious species, that is, those not evolving towards dioecy, inheritance of male sterility is probably mostly nuclear-cytoplasmic (Ross, 1978; Kheyr-Pour, 1980; Van Damme, 1983). With this mode of inheritance, maintenance of male sterility appears to depend on the pleiotropic effects of the genetic factors causing male sterility on fitness characters (Charlesworth, 1981; Delannay et al., 1981). In most experimental studies on the maintenance of the system, such as those mentioned above, self-compatible species have been used. Differences in seed production between sex types may then be due not only to pleiotropic effects of the male sterility genes, but also to differing pollination conditions and inbreeding depression in partially selfing hermaphrodites. Therefore fitness effects of male sterility genes cannot readily be shown in self-compatible species (Charlesworth, 1981). These problems of interpretation do not exist to the same extent in self-incompatible species like Plantago lanceolata. The combination of self-incompatibility and stable gynodioecy has been studied only rarely (Horovitz and Beiles, 1980) and to date no full account of such a case is available.

In preceding papers in this series it has been shown that the sex polymorphism in Plantago lanceolata is highly complex, consisting of three male sterility types with differences in flower morphology, mode of inheritance and distribution in the field (Van Damme and Van Delden, 1982; Van Damme, 1983). Here, two of the male sterility types (MS1, MS2) and the corresponding intermediate sex phenotypes (IN1, IN2) are examined further. They are compared to hermaphrodites $(\mathrm{H})$ under natural conditions for components of seed production and seed weight. Furthermore, differences within the hermaphroditic group are taken into account not only in seed-but also in pollen production. The aim is to investigate the importance of the reproductive phase for the maintenance of gynodioecy and to determine whether fitness effects can be ascribed to the male sterility genes.

\section{MATERIALS AND METHODS}

Plantago lanceolata is a perennial rosette herb with its flowers concentrated on spikes (for a description, see Cavers et al., 1980). The species is usually wind-pollinated although insect-pollination has been shown to be possible (Stelleman and Meeuse, 1976); it is self-incompatible (Ross, 1973) and gynodioecious (Darwin, 1877). The existence of two plasmon types has been shown (Van Damme and Van Delden, 1982). Plants with either plasmon type can be male sterile, intermediate or hermaphrodite and are accordingly designated MS1, IN1, H1 or MS2, IN2, H2. For details on the genetics of male sterility, see Van Damme (1983).

Sex types have studied in four populations: Anloo (An) and Groningen $(\mathrm{Gr})$ in the north, Heteren ( $\mathrm{He})$ in the east and Merrevliet $(\mathrm{Me})$ in the south-west of the Netherlands. These sites are all grasslands, differing in 
TABLE 1

Characteristics of four Plantago lanceolata populations. Sex type frequencies are taken from Van Damme and Van Delden (1982)

\begin{tabular}{|c|c|c|c|c|c|c|c|}
\hline \multirow[b]{2}{*}{ Population } & \multirow{2}{*}{$\begin{array}{c}\text { Site } \\
\text { description }\end{array}$} & \multirow[b]{2}{*}{ Mowing date } & \multicolumn{5}{|c|}{ Sex type frequencies } \\
\hline & & & MS1 & IN1 & MS2 & IN2 & $\mathbf{H}$ \\
\hline An & wet hayfield & late August & 0 & 0 & 0.082 & 0.013 & 0.905 \\
\hline $\mathrm{Gr}$ & $\begin{array}{l}\text { tall grass } \\
\text { between buildings }\end{array}$ & late August & $0 \cdot 086$ & 0.009 & $0 \cdot 055$ & $0 \cdot 018$ & 0.832 \\
\hline $\mathrm{He}$ & dry hayfield & June & $0 \cdot 220$ & 0.074 & 0.002 & 0.005 & 0.699 \\
\hline $\mathrm{Me}$ & wet hayfield & July & 0 & 0 & 0.039 & 0.055 & 0.906 \\
\hline
\end{tabular}

mowing regime and in sex type frequencies (table 1). Only in the $\mathrm{Gr}$ population were both sterility types studied. Within populations the distribution of male steriles was not random. Most striking was the situation in the An population, where 30 per cent of the plants in a $200 \mathrm{~m}^{2}$ area were MS2 whereas less than 1 per cent were MS2 in the main part of the sampling area. Seed predation by the cucurlionid Gymnetron labile was observed in 49 per cent of the plants in the He population, but at a low level $(<1$ per cent) and irrespective of sex type. It was therefore left out of consideration. For each sex type varying numbers of plants were tagged individually during the flowering period in the hayfields $\mathrm{He}, \mathrm{Me}$ and $\mathrm{An}$. In the first two populations all spikes of the tagged plants were harvested two days before mowing. In the late-mown An population spikes were collected at maturity during successive visits. In some cases single spikes from additional plants were taken. The Gr population was sampled by taking one mature spike per plant only. As MS1 and MS2 predominated in different parts of this population, each male sterility type was compared to hermaphrodites nearby in order to rule out microgeographical variation. Aftermath occurred in the early-mown He population, but this was only indirectly taken into account by determining sex type frequencies in both flowering periods. The following measurements were taken: number of spikes produced per plant; and for each spike, length, number of seeds, seed weight and, in separately collected material, the numbers of empty and seed bearing flowers. Number of seeds and flowers were calculated per $\mathrm{mm}$ spike and seed weight as weight per seed. In some plants shrivelled styles from empty capsules were taken and stained according to Martin's (1959) fluorescence technique, to check for pollination.

Some of the observations have been made on a series of reciprocal crosses between $\mathrm{H} 1$ and $\mathrm{H} 2$ hermaphrodites from $\mathrm{He}$ and $\mathrm{Gr}$ and from an additional population Westduinen (Wd). These crosses have been used previously in a genetic study (Van Damme and Van Delden, 1982). They were raised in blocks in an experimental garden with plasmon types alternating and reciprocals adjacent to each other. In order to check whether differences between plasmon types could be due to small scale environmental differences, reciprocal crosses between plants with identical plasmon types were used as controls. Progenies segregated varying proportions of hermaphrodites. From each progeny at least five hermaphrodites were examined. Besides measurements on components of seed weight production 
per spike, the following components of pollen production were also determined: anther length and width, and pollen fertility as inferred from pollen stainability according to Alexander (1969).

Prior to statistical analysis the data on number of spikes and seeds per plant and spike length were log transformed and data on pollen stainability arcsin transformed. Analyses of variance on spike characteristics were nested and, for weight per seed and seed-and flower number per mm spike, also weighted.

\section{Results}

Hermaphrodites with different plasmon types $(\mathrm{H} 1, \mathrm{H} 2)$ cannot be distinguished by means of flower morphology. Therefore they have been studied in a separate experiment, to be reported later in this section. In the field they were taken as one phenotype. The results of all field studies are shown in table 2. Male steriles will be compared first with hermaphrodites and then the intermediates will be considered.

\section{(i) Male steriles}

Ovule production. Ovule production has been measured as the product of the number of spikes per plant, spike length $(\mathrm{mm})$, number of flowers per mm spike and the number of ovules per flower. As the latter is almost invariably two in Plantago lanceolata, differences in flower production will be interpreted as differences in ovule production. Preliminary analyses showed that the two male sterility types differed in a similar way from hermaphrodites in all three variable components of ovule production. In the analyses in table 3 they are therefore treated as one sex type. The absence of significant interactions for all three components confirms that differences between male steriles and hermaphrodites do not noticeably depend on population or on male sterility type. As flower number per unit spike length does not differ between sex types, the product of spike number per plant and spike length can be used for relative ovule production. In both components male steriles appear superior to hermaphrodites (table 3 ), resulting in an average ovule production of male steriles relative to hermaphrodites of 1.69 , varying, in the populations in which both components have been determined, from 1.49 in An to 1.91 in Me. The results are consistent despite marked differences between populations (table 2).

Female fertility. It follows from the foregoing that seed number per $\mathrm{mm}$ spike is equivalent to seed number per ovule. This character is determined by female fertility, pollen availability and zygote viability due to its own genotype. As Plantago lanceolata is wind-pollinated and self-incompatible, pollination conditions and amount of inbreeding are not likely to differ between sexes within populations. So differences in seed number per mm spike can be interpreted as differences in female fertility. The two male sterility types were analysed separately in order to avoid obvious interactions (table 3). There are no differences in seed number per mm spike between MS1 and $\mathrm{H}$ plants while there is a strongly significant difference between MS2 and H, MS2 plants producing, on average, 30 per cent fewer seeds per mm spike. This male sterility type is thus also partially female sterile.

The overall effect on seed production of producing more ovules per plant but less seeds per ovule, was investigated in a separate analysis on 


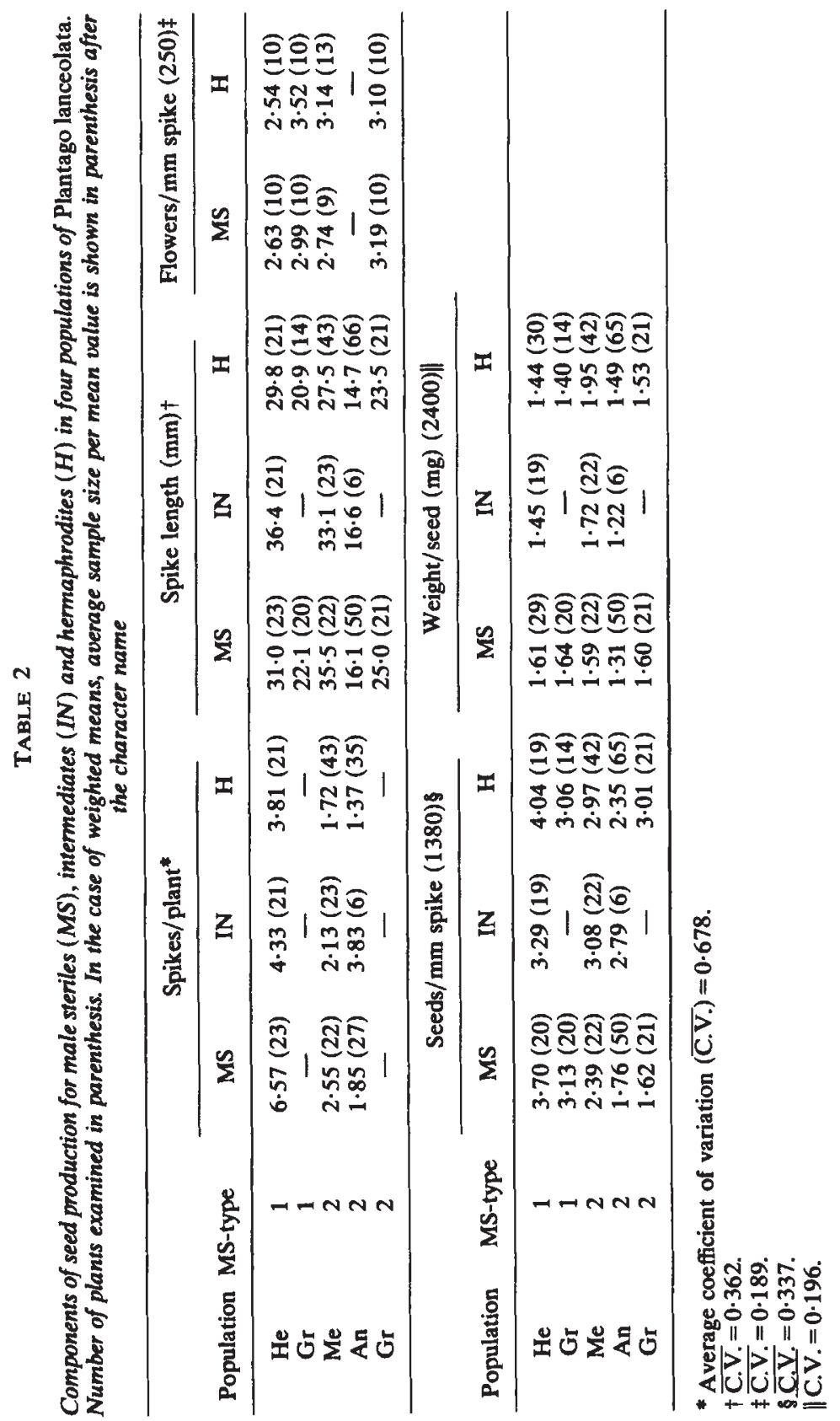




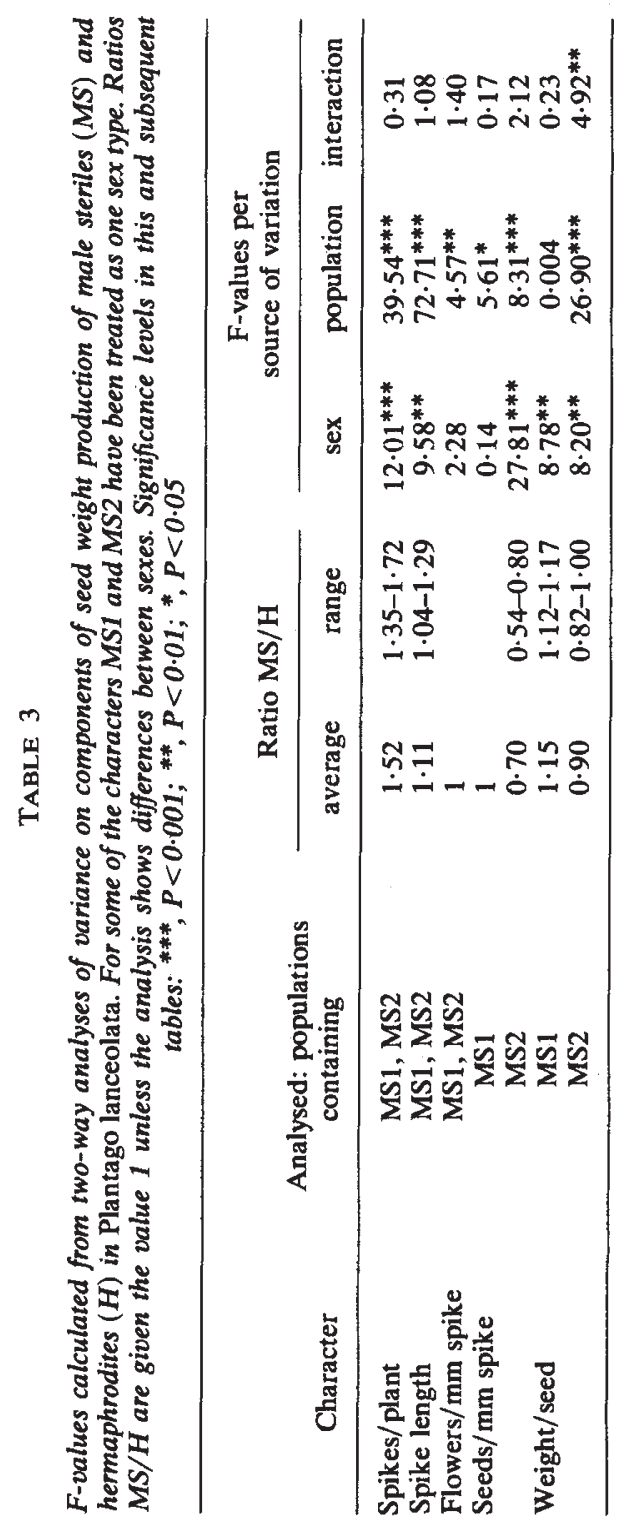


the data of the Me and An populations. Although, on average, MS2 plants produced more seeds than hermaphrodites $(\mathrm{MS} 2 / \mathrm{H}$ ratio: $1.69 \times 0.70=$ $1 \cdot 18$, table 3$)$, the difference was not significant $(P>0 \cdot 25)$.

Weight per seed. The results for weight per seed are also different for the two male sterility types (tables 2 and 3). MS1 plants produce 12-17 per cent heavier seeds than hermaphrodites. In contrast, MS2 plants produce lighter seeds, but here a significant interaction exists between sex and population. Subsequent analysis showed that weight per seed does differ significantly in the Me and An population, but not in the Gr population.

In the early mown $\mathrm{He}$ population the analysis was hampered because 26 per cent of all spikes had not fully matured at the time of mowing. Averaged over sex types immature spikes differed from mature spikes in seed number per mm spike $(2.84$ versus $3.67 ; P<0.01)$ and weight per seed $(0.84$ versus $1.51 \mathrm{mg} ; P<0.001)$. Results of immature spikes for these two characters are therefore not included in the tables 2, 3 and 5. Sex types did not differ in the fraction of immature spikes and both seed number per $\mathrm{mm}$ spike and weight per seed did not differ between sex types. As for weight per seed, this result may somewhat reduce the difference between MS1 and $\mathrm{H}$ plants in this population (table 2). A related complication appeared to be a second, but much more limited, flowering period after mowing. For this period only sex type frequencies have been determined: 18.6 per cent MS1, 11.0 per cent IN 1 and 0.5 per cent MS $2+$ IN2, the rest being hermaphrodite $(n=409)$. As these frequencies did not differ from those before mowing $(P>0 \cdot 10$; table 1$)$, any differences between sex types in propensity to flower are probably the same in the two flowering periods. Therefore the second period is assumed not to affect any of the results presented above.

In summary, MS1 plants perform better than hermaphrodites by producing both more and heavier seeds. On the other hand, MS2, being partially female sterile, produces no more seed, on average, than hermaphrodites; this seed, however, is lighter. Hence, MS2 plants do not appear to have any advantage over hermaphrodites in reproduction via seeds.

\section{(ii) Partial female sterility}

Direct evidence that pollination is not limiting seed set in MS2 was obtained by examining 116 styles of empty capsules from MS2 plants by means of fluorescence microscopy. In 76 styles remnants of pollen tubes could be seen, indicating that at least two thirds had been adequately pollinated. Interestingly, MS1 and $\mathrm{H}$ plants also have incomplete seed set: a comparison of flower- and seed numbers per mm spike in table 2 shows that they set only 1-1.5 seeds per flower though two ovules are present in each flower. Counts of empty and seed bearing capsules of plants from three populations in table 4 show, on the one hand, that MS2 plants have higher fractions of empty capsules $(P<0.001)$, as might be expected, but on the other hand MS1 and $\mathrm{H}$ plants also have considerable fractions of empty capsules (9-21 per cent). Furthermore, incomplete seed set on the last two sex types occurs even when the amount of pollen is not limited, because artificial pollination of ten MS1 individuals in a greenhouse yielded 886 capsules containing, on average, only 1.2 seeds while 21 per cent of the capsules were empty. The good correspondence between the results 
TABLE 4

Frequency of empty capsules on spikes of Plantago lanceolata, depending on population and sex type. Number of plants is given in parenthesis

\begin{tabular}{cccc}
\hline Population & Sex type & No. of capsules examined & Empty fraction \\
\hline $\mathrm{He}$ & $\mathrm{H}$ & $708(10)$ & $0 \cdot 19$ \\
& MS1 & $731(10)$ & $0 \cdot 16$ \\
$\mathrm{Gr}$ & $\mathrm{H}$ & $725(10)$ & $0 \cdot 21$ \\
& MS1 & $637(10)$ & $0 \cdot 15$ \\
$\mathrm{Me}$ & $\mathrm{H}$ & $1190(13)$ & $0 \cdot 09$ \\
& MS2 & $1007(9)$ & $0 \cdot 35$ \\
$\mathrm{Gr}$ & $\mathrm{H}$ & $657(10)$ & $0 \cdot 14$ \\
& MS2 & $730(10)$ & $0 \cdot 42$ \\
\hline
\end{tabular}

from the greenhouse and the field suggests that in all three forms pollination does not limit seed set in the field (cf. Bawa and Opler, 1975). Apparently in all sex types full seed set is prevented by some factor other than the limited availability of pollen.

\section{(iii) Intermediates}

The intermediate sex types, IN1 and IN2, are partially male sterile showing a wide range from complete male sterility to complete male fertility (Van Damme, 1983). Seed production of both types has been studied in a number of populations where they occur together with male steriles of similar type (table 2). The results are presented in table 5 as ratios IN/MS and IN/H, together with population averages for seed production, its components and weight per seed.

The IN1 phenotype, which has been studied only in the He population, appears intermediate between MS1 and $\mathrm{H}$ in both ser d production and weight per seed (table 5). As for the components of se :d production, IN1 plants appear to have somewhat longer spikes and less seeds per $\mathrm{mm}$ spike, though none of these differences are significant.

The results for the IN2 phenotype show strongly significant differences between sex types (table 5). Thus, in both populations, Me and An, where IN2 plants have been studied, the IN2 forms have a seed number per mm spike equal to that of hermaphrodites, but clearly higher than that of the male steriles. Their female fertility, therefore, equals that of hermaphrodites. On the other hand, weight per seed in IN2 plants is significantly lower than in hermaphrodites and equals that of MS2 plants. For ovuleand seed production the results are different in the two populations. IN2 plants in the An population have a substantially higher ovule- and seed production than either MS2 and H plants, because of a higher spike number per plant (table 5), while in the Me population there are no significant differences with MS2 and $\mathrm{H}$ plants. Considering total seed production and weight per seed, the IN2 phenotype in Me population equals MS2 in having the same seed production and a lower weight per seed relative to hermaphrodites. In the An population, on the other hand, plants of the IN2 phenotype produce 3.4-3.8 times more seed than MS2 and H plants. 


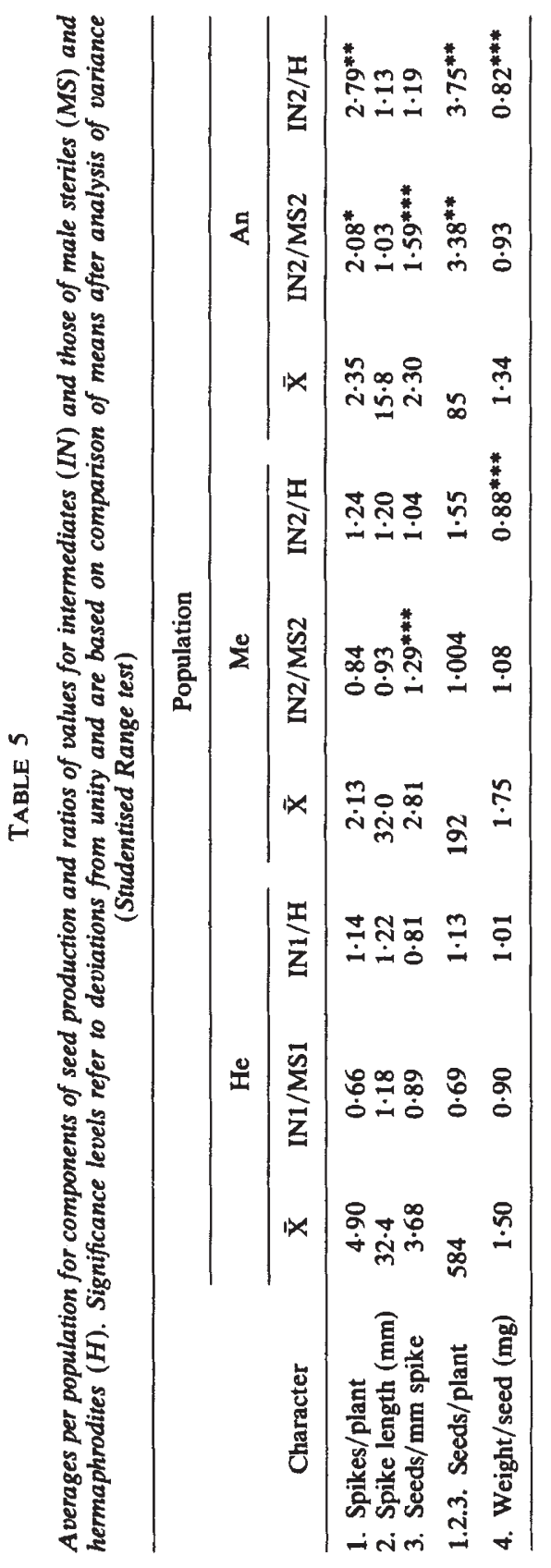




\section{(iv) Hermaphrodites}

Hermaphrodites in Plantago lanceolata form a heterogeneous group with respect to male sterility genes (Van Damme, 1983). Apart from variation in nuclear genes they are divided into two groups, $\mathrm{H} 1$ and $\mathrm{H} 2$, depending on their plasmon type. These two hermaphroditic types can only be distinguished by progeny tests, or by a knowledge of the plasmon type of their female parents. Components of pollen and seed production of $\mathrm{H} 1$ and $\mathrm{H} 2$ plants were investigated in a series of reciprocal crosses between plants with different plasmon types (table 6). Hermaphrodites in progenies of reciprocal crosses will have a similar nuclear background but differ in plasmon type. All comparisons have been made on a per spike basis. For spike length, seed number per mm spike and weight per seed no differences between reciprocals were found. In cultivation $\mathrm{H} 1$ and $\mathrm{H} 2$ plants apparently do not differ in seed output. In reproduction via pollen, however, highly significant differences exist. $\mathrm{H} 1$ plants are superior to $\mathrm{H} 2$ plants in anther length and width, resulting in an estimated difference in anther volume of $\mathrm{H} 1$ relative to $\mathrm{H} 2$ of $1 \cdot 24$. As pollen stainability and spike length do not differ between $\mathrm{H} 1$ and $\mathrm{H} 2$, the 24 per cent difference in an ther size probably also applies to pollen production per spike. The involvement of nuclear genetic background in determining components of reproduction appears from differences between progenies of different parents and from the significant interaction in the analysis of anther length (table 6). Several crosses between plants with identical plasmon type were taken as controls for all characters in table 6 except for pollen stainability. In 20 out of 22 cases differences between reciprocals were non-significant and the remaining two cases, involving anther width were only just- significant $(0.025<P<$ $0 \cdot 050)$. This accords with theoretical expectation.

\section{Discussion}

\section{(i) Differences in sexual reproduction}

The main purpose of this study was to investigate whether male steriles in Plantago lanceolata compensate for their loss of function as males in the reproductive part of the life cycle. A comparison of components of seed production per year has been made between the two male sterility types (MS1, MS2), the corresponding partial male sterility types (IN1, IN2) and hermaphrodites $(\mathrm{H})$. In all three components, ovule production, seed number per ovule and weight per seed, differences between sex types have been found. Both MS1 and MS2 have a higher ovule production than $\mathrm{H}$, but they differ from each other in seed number per ovule and weight per seed (table 3). Other studies on this subject have shown that there is also variation between species in the way male steriles differ from hermaphrodites. Examples are given in table 7. Components of seed production in the table are represented on a per flower basis. In Thymus vulgaris, the larger seed production of male steriles relative to hermaphrodites is brought about by a difference in seed number per flower (Assouad et al., 1978). In contrast, Stellaria longipes has a lower seed number per flower in male steriles than in hermaphrodites, while numbers of ovules per flower are the same. Nevertheless, due to their greater flower production, male steriles in this species produce more seeds than hermaphrodites (Philipp, 1980). This 


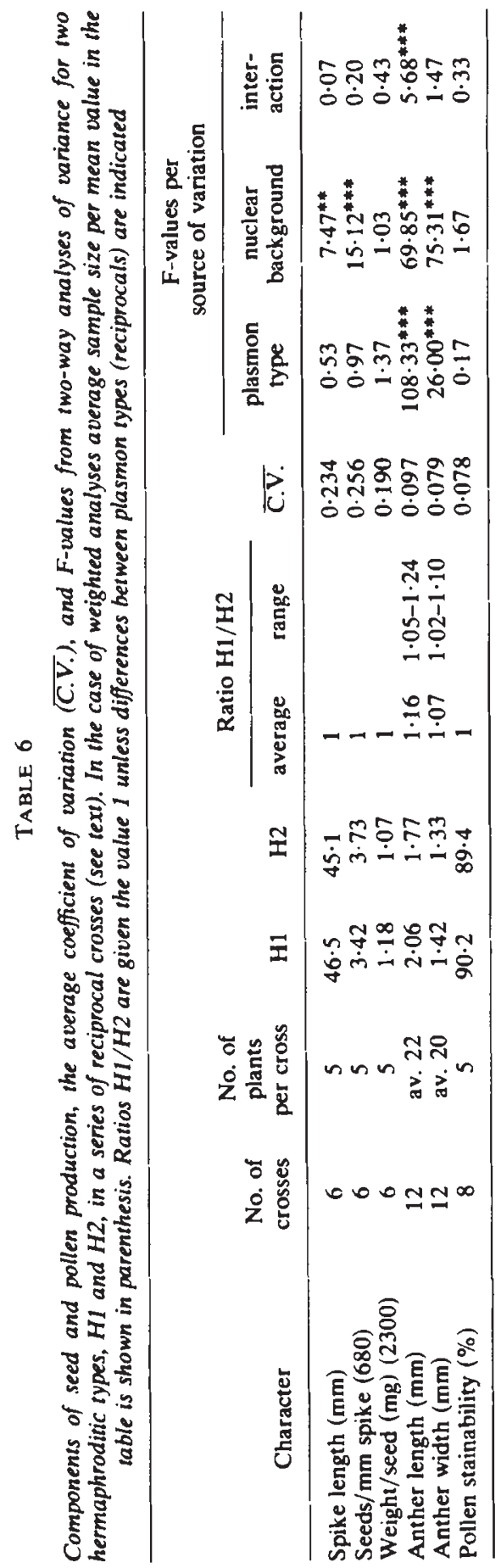


TABLE 7

Contribution of male steriles relative to that of hermaphrodites $(M S / H)$ in components of seed production in several gynodieocious species

\begin{tabular}{|c|c|c|c|c|}
\hline Species & Author & $\begin{array}{c}\text { Flowers/ } \\
\text { plant }\end{array}$ & $\begin{array}{l}\text { Seeds/ } \\
\text { flower }\end{array}$ & $\begin{array}{c}\text { Weight/ } \\
\text { seed }\end{array}$ \\
\hline Plantago lanceolata & Present author & & & \\
\hline MS1 & & 1.69 & 1 & $1 \cdot 15$ \\
\hline MS2 & & 1.69 & 0.70 & 0.90 \\
\hline Geranium sylvaticum & $\begin{array}{l}\text { Vaarama and } \\
\text { Jääskeläinen, } 1967\end{array}$ & $0.69^{+}$ & 1 & $0.90^{ \pm}$ \\
\hline Stellaria longipes & Philipp, 1980 & $1 \cdot 9$ & 0.84 & - \\
\hline Thymus vulgaris & Assouad et al., 1978 & 1 & $2 \cdot 2-3 \cdot 3$ & - \\
\hline Cortaderia selloana & Connor, 1973 & - & $2 \cdot 1$ & 1.47 \\
\hline $\begin{array}{l}\text { apioid Umbelliferae } \\
\text { (15 species) }\end{array}$ & Webb, 1982 & $0 \cdot 2-1$ & $1 \cdot 7-50$ & 1 \\
\hline
\end{tabular}

+ per shoot.

\pm estimated from difference in seed size.

situation is similar to that for MS2, except that MS2 plants appear to have no advantage over hermaphrodites because the difference in seed production between sex types was not significant. The MS2 plants may even have a disadvantage because of a lower weight per seed. A distinct disadvantage of male steriles has been found in Geranium sylvaticum (Vaarama and Jääskeläinen, 1967). An explanation for maintenance of male sterility in these cases may be found either in heterogeneity among genotypes within sex phenotypes (e.g., overdominance) or in other parts of the life cycle than the reproductive phase. The other examples in table 7 are Cortaderia selloana (Connor, 1973) and a group of 15 species from the apioid Umbelliferae, which show a transition from gynodioecy towards subdioecy (Webb, 1981). Thus, there is much variation in the way by which male sterile forms are maintained in the population, a conclusion which holds both in comparisons between species as well as between male sterile types within Plantago lanceolata.

Differences between male steriles and hermaphrodites in Plantago lanceolata have also been found by Krohne et al. (1980) and Primack (1978). According to personal communications both authors have probably been working with MS1. Their results, showing differences between sex types in flower production or in the biomass allocated to reproductive parts and in weight per seed, agree well with those in the present paper. However, in both studies differences were obtained only in some environments and not in others. A similar heterogeneity in the present study was found for type 2 sterility. The IN2 plants have a far higher spike production than male steriles and hermaphrodites in one out of two populations (table 5), which might be due to differences in genetic composition of the two populations (Van Damme, 1983) or to environmental influences (see also Van Damme and Van Delden, 1982). Intermediate sex types have only rarely been taken into account in studies of the maintenance of male sterility. However, Philipp (1980) showed in a cultivation experiment that intermediate sex types in Stellaria longipes produced twice as many flowers as hermaphrodites and slightly more than male steriles. The same lack of data exists with respect 
to reproduction via pollen in hermaphrodites. Young (1972) found differences in pollen fertility in two Rhus species between hermaphrodites with ample and with no seed set respectively, in that pollen fertility was lower when seed was set. In Plantago lanceolata differences in pollen production were found, not in pollen fertility, and they were correlated with the plasmon type of the hermaphrodites and not with their seed production (table 6).

\section{(ii) Partial female sterility}

Plantago lanceolata has repeatedly been reported to have incomplete seed set in the field (Dowling, 1935; Primack and Antonovics, 1981; Cavers et al., 1980; Stelleman, 1982). It has been shown in the present paper that this is also true after abundant artificial pollination. Hence, incomplete seed set in the field in any sex type is unlikely to be due to poor pollination. Full seed set was obtained by Primack and Antonovics (1981) on plants that were grown at high density in "high nutrient conditions", but not in "low nutrient conditions". Resource availability apparently may limit seed set in Plantago lanceolata, a phenomenon which has been observed in many species (Stephenson, 1981). That pollination is not limiting seed set, was explicitly shown for the partially female sterile MS2 phenotype. The same mechanism as in other sex types may operate in MS2.

Circumstantial evidence for this comes from the difficulties encountered in crosses with MS2 which were due to weak scapes (Van Damme, 1983), indicating that the vascular system in MS2 plants may have a lower transport capacity than in other sex types. In addition, the distribution of empty capsules over spikes seems not to differ between MS2 and other sex types. Alternative explanations involve ovule fertility and non-functioning styles. The latter possibility is indicated by occasional observations of stomata between the papillae of the style, which is not normal. Once I observed numerous tubes from germinated pollen grains circling around the style, apparently not able to enter it. These observations suggest that styles of MS2 flowers sometimes have a leaflike appearance. Probably all three mechanisms contribute to the partial female sterility of MS2 plants.

Partial female sterility associated with male sterility has also been found in some cultivated species (Cutter and Bingham, 1977; Tsikov and Nikova, 1980, see also Ross, 1977). However, the decreased seed set appears in most of these cases to be due to a decrease in pollinator activity on male sterile plants (e.g. Radford and Rhodes, 1978; Erickson et al., 1979). Pollinating insects in these cases are attracted by nectar which is absent in male sterile mutants. In gynodioecious species which are regularly insectpollinated, this problem apparently does not exist (Burrows, 1960; Young, 1972; Arroyo and Raven, 1975). In Thymus vulgaris, for example, the higher seed set per flower in male steriles can be ascribed partly to a more efficient pollination of male sterile flowers (Assouad et al., 1978). In Plantago lanceolata insects visiting plantains are only offered pollen (Stelleman and Meeuse, 1976); thus reduced pollination and hence reduced seed set of male steriles in Plantago lanceolata may be expected in populations where insect pollination contributes significantly to seed set. Such populations are known to exist (Stelleman, 1982), but none of those in the present study are of this kind. 


\section{(iii) Mechanisms for maintenance}

Several mechanisms have been proposed by which male steriles may be maintained in natural populations. In theoretical models it has been shown that outbreeding advantage of male steriles results in the maintenance of the system provided that it exceeds a critical value (Lloyd, 1975; Charlesworth and Charlesworth, 1978). While it is probably an important mechanism in self-compatible species, like Thymus vulgaris (Assouad et al., 1978; Perrot et al., 1982), this is unlikely in self-incompatible species, such as Plantago lanceolata.

The combination of gynodioecy and self-incompatibility has been reported in a limited number of species: Plantago lanceolata and $P$. maritima (Ross, 1970), Hirschfeldia incana (Horovitz and Galil, 1972), and possibly, two Rhus species (Young, 1972) and Cortaderia selloana (Connor, 1973). The last two cases are better regarded as subdioecious. Self-incompatibility has arisen either once or a few times in the early Angiosperms (Crowe, 1964), and Plantago lanceolata has a one-locus gametophytic incompatibility system (Ross, 1973), which is considered primitive in Angiosperms. Little is known about the evolution of gynodioecy but it seems very likely that it arose in Plantago lanceolata or in an ancestral species after selfincompatibility. As has been pointed out in preceeding sections, in these circumstances differences in reproduction between sex types may be interpreted directly in terms of fitness effects of the underlying male sterility genotypes. Nuclear male sterility genes may show overdominance or in teractions between each other with respect to these pleiotropic fitness effects. On this view the so-called "compensation effect" (Charlesworth and Charlesworth, 1978) or "phenotypic effect" (Delannay et al., 1981; Charlesworth, 1981) is to be regarded as due to pleiotropy with non-multiplicative interaction between genes.

The MS2 phenotype differs from that of $\mathrm{H}$ plants in flower morphology, in male and female functioning and in weight per seed, which are all closely associated in plant development and hence likely to be due to the MS2 genotype. Such complexes have also been observed in other species (Connor, 1973; Assouad et al., 1978). Other differences between sex types, as in spike production per plant, might also result from pleiotropy of the male sterility genes. The discovery of physiological differences between male steriles and hermaphrodites in the vegetative part of the plants makes such connections imaginable (see Pearson, 1981). Particulary interesting are differences in hormonal balance (Sawhney, 1974; Louis and Durand, 1978; Ahokas, 1982) because plant hormones are known to act upon a variety of developmentally unlinked processes. However, mutations affecting both male function and other fitness characters in such a specific way, must be rare and it would take several of them to explain the complex situation in Plantago lanceolata. The organisation of plant development probably imposes restraints on the occurrence of such mutations. If pleiotropism is important in the maintenance of gynodioecy, differences in these restraints might provide an explanation for the observed differences between plant families in the incidence of gynodioecy (cf. Delannay, 1978).

An alternative explanation comes from Ross (1978). He suggested that male sterility becomes initially established by the occurrence of a male sterility mutation, linked to an overdominant chromosome segment. 
Apparent pleiotropy would then evolve because complete linkage of a gene, increasing seed production, to the male sterility gene would be favoured. Whether pleiotropy in any case is due to the male sterility genes themselves or to closely linked genes, is hard to decide. Some evidence in favour of the presence of overdominance in Plantago lanceolata was found in the An population where IN2 plants greatly exceeded both MS2 and $\mathrm{H}$ plants in seed production (table 5). It has been shown in a genetical study that the IN2 phenotype possibly results from incomplete dominance at the MS2-loci (Van Damme, 1983). This suggests, despite the partial male sterility of IN2 plants, that overdominance with respect to fitness at the sex loci is involved in the maintenance of MS2 (cf. Ross and Weir, 1975; Ross, 1980). The data for IN1 (table 5) allows no definite conclusions, but it will be shown in a next paper that a similar situation exists for type 1 sterility (Van Damme, in preparation).

\section{(iv) Comparison with theoretical models}

Both male sterility types that were studied in this paper, have nuclearcytoplasmic inheritance (Van Damme and Van Delden, 1982; Van Damme, 1983). Theoretical models for the maintenance of male sterility with this mode of inheritance have indicated that fitness effects should be associated with male sterility factors (Charlesworth, 1981; Delannay et al., 1981). A prediction of the models is that fitness differences will exist between sex genotypes within sex phenotypes. Such a difference has been found for Plantago lanceolata in pollen production between $\mathrm{H} 1$ and $\mathrm{H} 2$ plants. The cultivation experiment suggests that the effect can be ascribed to the difference in plasmon type between $\mathrm{H} 1$ and $\mathrm{H} 2$. However, the reciprocal crosses segregated male steriles in most cases and MS1 and MS2 are determined by different nuclear genes (Van Damme, 1983), implying that nuclear genes may partly be responsible for the observed difference. Pollen fertility, differing between hermaphrodite genotypes has been taken into account in a few models (Ho and Ross, 1973; Ross and Weir, 1975; Gregorius et al., 1982) but in most models fitness effects are assumed to act on female fertilities only.

All sex phenotypes, with MS2 as a possible exception (Van Damme, 1983), consist of multiple genotypes, which here have been studied collectively, so that fitness effects of individual nuclear male sterility genes could not be detected. This makes it difficult to ascertain with the models presently available, to what extent the observed differences in sexual reproduction are sufficient to explain the presence of male sterility in Plantago lanceolata. It has been shown by Van Damme and Van Delden (1982) that MS1 occurs in much higher frequencies in natural populations than MS2, the maxima being 23 per cent and 9.6 per cent respectively. There is a positive correlation between these figures and the relative fitnesses of MS1 and MS2 (table 3), but it seems clear that the present results do not fully explain the situation, for the MS2 phenotype apparently has no advantage in reproducing as a female. It generally occurs in only low frequencies (Van Damme and Van Delden, 1982), except in the An population, where up to 30 per cent have been found. Overdominance was suggested as a mechanism for the maintenance of MS2 in this population, but differences between sex types in other parts of the life cycle might also be responsible. In a later paper (Van 
Damme, in preparation) other life cycle characters than reproduction will be considered.

Acknowledgements. I thank Drs M. Bos, D. Charlesworth, M. Ross, G. van Nigtevecht, W. van Delden and J. Woldendorp, for critically reading earlier drafts of the manuscript, and $T$. van Gijzen for identifying the beetle species. These investigations were supported by BION-ZWO.

\section{REFERENCES}

AHOKAS, H. 1982. Cytoplasmic male sterility in barley: evidence for the involvement of cytokinins in fertility restoration. Proc. Natl. Acad. Sci. USA, 79, 7605-7608.

ALEXANDER. M. P. 1969. Differential staining of aborted and nonaborted pollen. Stain Techn., $44,117-122$.

ARROYO, M. T. K. AND RAVEN, P. H. 1975. The evolution of subdioecy in morphologically gynodioecious species of Fuchsia sect. Encliandra (Onagraceae). Evolution, 29, 500-511.

ASSOUAD, M. W., DOMMEE, B., LUMARET, R. AND VALDEYRON, G. 1978. Reproductive capacities in the sexual forms of the gynodioecious species Thymus vulgaris L. Bot. J. Linn. Soc., 77, 29-39.

BAWA, K. S. AND OPLER, P. A. 1975. Dioecism in tropical forest trees. Evolution, 29, 167-179. BURROWS, C. J. 1960. Studies in Pimelea. I. The breeding system. Trans. Roy. Soc. N.Z., 88, 29-45.

CA VERS, P. B., BASSETT, I. J. AND CROMPTON, C. W. 1980. The biology of canadian weeds. 47. Plantago lanceolata L. Can. J. Plant Sci., 60, 1269-1282.

CHARLESWORTH, B. AND CHARLESWORTH, D. 1978. A model for the evolution of dioecy and gynodioecy. Amer. Nat., 112, 975-997.

CHARLESWORTH, D. 1981. A further study of the problem of the maintenance of females in gynodioecious species. Heredity, 46, 27-39.

CONNOR, H. E. 1973. Breeding systems in Cortaderia (Gramineae). Evolution, 27, 663-678.

CROWE, L. K. 1964. The evolution of outbreeding in plants. Heredity, 19, 434-457.

CUTTER, G. L. AND BINGHAM, E. T. 1977. Effect of soybean male-sterile gene $\mathrm{ms}_{1}$ on organisation and function of the female gametophyte. Crop. Sci., 17, 760-764.

DARWIN, C. 1877. Different forms of flowers on plants of the same species. John Murray, London. DELANNAY, X. 1978. La gynodioécie chez les angiospermes. Natur. belges, 59, 223-237.

DELANNAY, X., GOUYON, P. H. AND VALDEYRON, G. 1981. Mathematical study of the evolution of gynodioecy with cytoplasmic inheritance under the effect of a nuclear restorer gene. Genetics, 99, 169-181.

Dowling, R. E. 1935. The structure of the ovary in the genus Plantago L. I The British species. J. Linn. Soc. (Bot.), 50, 329-336.

ERICKSON, E. H., PETERSON, C. E. AND WERNER, P. 1979. Honey bee foraging and resultant seed set among male-fertile and cytoplasmically male sterile carrot inbreds and hybrid seed parents. J. Amer. Soc. Hort. Sci., 104, 635-638.

GREGORIUS, H.-R., ROSS, M. D. AND GILLET, E. 1982. Selection in plant populations of effectively infinite size: III. The maintenance of females among hermaphrodites for a biallelic model. Heredity, 48, 329-343.

HO, T.-Y. AND ROSS, M. D. 1973. Maintenance of male sterility in plant populations. II. Heterotic models. Heredity, 31, 282-286.

HOROVITZ, A. AND BEILES, A. 1980. Gynodioecy as a possible populational strategy for increasing reproductive output. Theor. Appl. Genet., 57, 11-15.

HOROVITZ, A. AND GALIL, J. 1972. Gynodioecism in east mediterranean Hirschfeldia incana, Cruciferae. Bot. Gaz., 133, 127-131.

KHEYR-POUR, A. 1980. Nucleo-cytoplasmic polymorphism for male sterility in Origanum vulgare L. J. Hered., 71, 253-260.

KROHNE, D. T., BAKER, I. AND BAKER, H. G. 1980. The maintenance of the gynodioecious breeding system in Plantago lanceolata L. Amer. Midl. Natur., 103, 269-279.

LLOYD, D. G. 1974. Theoretical sex ratios of dioecious and gynodioecious angiosperms. Heredity, 32, 11-34.

LLOYD, D. G. 1975. The maintenance of gynodioecy and androdioecy in angiosperms. Genetica, 45, 325-339. 
LOUIS, J. P. AND DURAND, B. 1978. Studies with the dioecious angiosperm Mercurialis annua L. $(2 n=16)$. Correlation between genic and cytoplasmic male sterility, sex segregation and feminizing hormones (cytokinins). Molec. Gen. Genet., 165, 309-322.

MARTIN, F. W. 1959. Staining and observing pollen tubes in the style by means of fluorescence. Stain Technol., 34, 125-128.

PEARSON, O. H. 1981. Nature and mechanisms of cytoplasmic male sterility in plants; a review. Hort. Sci., 16, $482-487$.

PERROT, V., DOMMÉE, B. AND JACQUARD, P. 1982. Etude expérimentale de la concurrence entre individus issus d'autofécondation et d'allofécondation chez le thym (Thymus vulgaris L.). Acta Oecologica, Oecol. Plant., 3, 171-184.

PHILIPP, M. 1980. Reproductive biology of Stellaria longipes Goldie as revealed by a cultivation experiment. New Phytol., 85, 557-569.

PRIMACK, R. B. 1978. Evolutionary aspects of wind pollination in the genus Plantago (Plantaginaceae). New Phytol., 81, 449-458.

PRIMACK, R. B. AND ANTONOVICS, J. 1981. Experimental ecological genetics in Plantago $V$ Components of seed yield in the ribwort plantain Plantago lanceolata L. Evolution, 35, 1069-1079.

RADFORD, B. J. AND RHODES, J. W. 1978. Effect of honeybee activity on the cross-pollination of male-sterile sunflowers. Queensl. J. Agric. An. Sci., 35, 153-157.

ROSS, M. D. 1970. Breeding systems in Plantago. Heredity, 25, 129-133.

ROSS, M. D. 1973. Inheritance of self-incompatibility in Plantago lanceolata. Heredity, 30, 169-176.

ROSS, M. D. 1977. Behaviour of a sex-differential fertility gene in hermaphrodite populations. Heredity, 38, 279-290.

ROSS, M. D. 1978. The evolution of gynodioecy and dioecy. Evolution 32, 174-188.

ROSS, M. D. 1980. The evolution and decay of overdominance during the evolution of gynodioecy, subdioecy, and dioecy. Am. Nat., 116, 607-620.

ROSS, M. D. AND WEIR, B. S. 1975. Maintenance of male sterility in plant populations. III Mixed selfing and random mating. Heredity, 35, 21-29.

SAWHNEY, V. K. 1974. Morphogenesis of the stamenless-2 mutant in tomato. III Relative levels of gibberellins in the normal and mutant plants. J. Exp. Bot., 25, 1004-1009.

STElleman, P. 1982. De betekenis van biotische bestuiving bij Plantago lanceolata. Thesis, Univ. of Amsterdam.

STELLEMAN, P. AND MEEUSE, A. D. J. 1976. Anthecological relations between reputedly anemophilous flowers and syrphid flies. I The possible role of syrphid flies as pollinators of Plantago. Tijdschr. Entom., 119, 15-31.

STEPHENSON, A. G. 1981. Flower and fruit abortion: proximate causes and ultimate functions. Ann. Rev. Ecol. Syst., 12, 253-279.

TSIKOV, D. AND NIKOVA, V. 1980. Male sterility in tobacco (Nicotiana tabacum): 4. Seed productivity. Genet. Sel., 13, 198-205.

VAARAMA, A. AND JÄÄSKELÄINEN, O. 1967. Studies on gynodioecism in the Finnish populations of Geranium sylvaticum L. Ann Acad. Sci. Fenn. Ser. A. Biologica, 108, 3-39.

VAN DAMME, J. M. M. 1983. Gynodioecy in Plantago lanceolata L. II. Inheritance of three male sterility types. Heredity, 50, 253-273.

VAN DAMME, J. M. M. AND VAN DELDEN, W. 1982. Gynodioecy in Plantago lanceolata L. I. Polymorphism for plasmon type. Heredity, 49, 305-320.

WEBB, C. J. 1979. Breeding systems and the evolution of dioecy in New Zealand apioid Umbelliferae. Evolution, 33, 662-672.

WEBB, C. J. 1981. Test of a model predicting equilibrium frequencies of females in populations of gynodioecious angiosperms. Heredity, 46, 397-405.

YOUNG, D. A. 1972. The reproductive biology of Rhus integrifolia and Rhus ovata (Anacardiaceae). Evolution, 26, 406-414. 